\title{
Behavioral responses of the woolly whitefly Aleurothrixus floccosus (Hemiptera: Aleyrodidae) to volatile organic compounds emitted from Citrus at laboratory conditions
}

\author{
Tommy Rioja ${ }^{1}$, Víctor Tello ${ }^{1}$, Natalí Fernandez ${ }^{2}$, and Ricardo Ceballos ${ }^{2^{*}}$ \\ ${ }^{1}$ Universidad Arturo Prat, Facultad de Recursos Naturales Renovables, Campus Huayquique, Av. Arturo Prat s/n, Iquique, Chile. \\ ${ }^{2}$ Instituto de Investigaciones Agropecuarias, INIA Quilamapu, Av. Vicente Méndez 515, Chillán, Chile. \\ "Corresponding author (rceballos@inia.cl).
}

Received: 12 April 2021; Accepted: 12 August 2021; doi:10.4067/S0718-58392021000400568

\begin{abstract}
Insects use biogenic volatile organic compounds (BVOCs) as chemical cues to find their host plants and colonize them. Studies of olfactory responses have reported that BVOCs released by host plants attract whiteflies. The citrus woolly whitefly, Aleurothrixus floccosus (Maskell) (Hemiptera: Aleyrodidae) is a serious foliar pest, infesting citrus orchards at the Pica Oasis, Tarapacá Region, Chile. We studied the attractant behavior of A. floccosus toward BVOCs emitted from lime (Citrus xaurantiifolia (Christm.) Swingle), mandarin (Citrus reticulata Blanco), and tangelo (Citrus reticulata $\times$ Citrus xparadisi Macfad.) shoots. We collected volatiles from living plants using dynamic headspace technique for $24 \mathrm{~h}$. The BVOCs released by the Citrus species were collected on Porapak Q traps and analyzed by gas chromatography coupled to mass spectrometry (GC-MS). The chemical analysis revealed differences in abundances of monoterpenes, sesquiterpenes and aldehydes; thus, D-limonene (33.44\%) was the most abundant compound in lime and significantly higher than mandarin and tangelo. On the other hand, sabinene (12.36\%), nonanal (28.06\%) and caryophyllene (22.97\%) were more abundant in mandarin. Tangelo showed high abundance of $\beta$-phellandrene (17.01\%), nonanal (17.87\%) and caryophyllene (16.01\%). In the two-choice bioassays, we found $13.5 \%$ and $17.1 \%$ more A. floccosus females in lime than in mandarin and tangelo, respectively. Our findings show that the volatile profile of 'Limón de Pica', C. aurantiifolia, elicits the strongest attractive behavior of A. floccosus females in the olfactometry experiments.
\end{abstract}

Key words: BVOCs, Citrus, olfactometric bioassay, woolly whitefly.

\section{INTRODUCTION}

The woolly whitefly, Aleurothrixus floccosus (Maskell) (Hemiptera: Aleyrodidae) is a serious foliar citrus pest worldwide, recorded in America, Mediterranean area, Iran, Africa, and some countries of Asia (India, Philippines, Taiwan, and Japan) (Giliomee and Millar, 2009; Belay et al., 2011; Sundararaj et al., 2020). A. floccosus feeds on lemon (Citrus xlimon (L.) Burm. f.), lime (Citrus xaurantiifolia (Christm.) Swingle), mandarin (Citrus reticulata Blanco), orange (Citrus $\times$ sinensis (L.) Osbeck), tangelo (Citrus reticulata $\times$ Citrus $\times$ paradisi), and grapefruit (Citrus $\times$ paradisi Macfad.) This pest has even been recorded on guava (Psidium guajava L.) and lucuma (Pouteria lucuma (Ruiz \& Pav.) Kuntze) (Tello et al., 2014). Whiteflies feed and oviposit on the abaxial surfaces of young citrus leaves and cover them with a woolly mass of filaments and honeydew secreted by sedentary nymphal stages (Tello et al., 2014). 
In Chile, A. floccosus is present from north to central regions including Arica y Parinacota, Tarapacá, Atacama, Coquimbo and Biobío (Klein Koch and Waterhouse, 2000). In northern regions, A. floccosus has seven generations per year, overlapping its population, attacking persistently citrus orchards at the Pica Oasis (Tello et al., 2019). In addition, the citrus species lime, mandarin, orange, tangelo and grapefruits are mainly cultivated in Tarapacá Region (ODEPA-CIREN, 2019). The citrus woolly whitefly colonizes young yellowish green leaves to oviposit its eggs (Walker and Zareh, 1990). Johnston and Martini (2020) showed that the silverleaf whitefly Bemisia tabaci Gennadius (Hemiptera: Aleyrodidae) was attracted to the yellow color; however, when it was offered combined visual and olfactory cues from tomato (Lycopersicon esculentum) plants, the attraction was stronger, indicating that whiteflies use both visual and chemical cues to find their host plants.

Plants emit biogenic volatile organic compounds (BVOCs) into the ecosystems, which serve as chemical cues to diverse organisms eliciting interactions between them (Kigathi et al., 2019). Moreover, herbivorous arthropods use BVOCs to find their host plants for feeding, oviposition, and shelter (Bouwmeester et al., 2019; Markheiser et al., 2020; Rioja et al., 2021). The greenhouse whitefly, Trialeurodes vaporariorum Westwood (Hemiptera: Aleyrodidae) has shown attraction to volatiles emitted from tomato and eggplant (Solanum melongena) (Darshanee et al., 2017). In addition, B. tabacci has shown attraction to volatiles emitted from uninfested chili (Capsicum annиum) plants (Saad et al., 2013). Hence, the emitted BVOCs from plants are used by whiteflies as chemical cues to find their host plants. Despite the information, olfactory responses of A. floccosus to BVOCs from citrus plants have not yet been explored. This gap in the research led us to examine olfactory responses of A. floccosus toward BVOCs released from living plants of lime, mandarin, and tangelo using two-choice bioassays in laboratory conditions to determine its preference by the citrus species.

\section{MATERIALS AND METHODS}

\section{Insects}

Adult females of Aleurothrixus floccosus (Maskell) (Hemiptera: Aleyrodidae) were obtained from citrus orchards in Pica Oasis (19 $58^{\prime}$ S, 69 $4{ }^{\circ}$ ' W; 1117 m a.s.1.), Tarapacá Region, Chile. Twigs of orange (Citrus $\times$ sinensis (L.) Osbeck) trees infested with nymphs of A. floccosus were cut and transferred into Flanders cages $(50 \times 30 \times 40 \mathrm{~cm})$ with a glass top and two muslin sleeves on the side, which were kept under laboratory conditions at $25 \pm 2^{\circ} \mathrm{C}, 60 \pm 10 \% \mathrm{RH}$ and $16: 8 \mathrm{~h}$ photoperiod. We placed emerged insects in another Flanders cage with C. sinensis shoots to feed them. Thus, 48-h-old emerged females of A. floccosus were used in the behavioral two-choice bioassays.

\section{Citrus plants and biogenic volatile organic compounds (BVOCs) collection}

Two-year-old plants of lime (Citrus xaurantiifolia (Christm.) Swingle) ecotype 'Limón de Pica', mandarin (Citrus reticulata Blanco) 'Oronules', and tangelo (Citrus reticulata $\times$ Citrus xparadisi Macfad.) 'Minneola' were used; all citrus plants grafted on 'Macrophylla' (Citrus macrophylla Wester) rootstock were kept in a white mesh greenhouse $(3 \times 2.5 \times 4 \mathrm{~m})$, under semi-field conditions in Iquique $\left(20^{\circ} 16^{\prime} \mathrm{S}, 70^{\circ} 07^{\prime} \mathrm{W}\right)$, Tarapacá Region, Chile. We cultivated plants in $7 \mathrm{~L}$ containers filled with organic soil and peat, which were fertilized (Ultrasol 18-18-18, Soquimich, Santiago, Chile), and irrigated suitably. A shoot from the middle zone of each citrus plant was selected, with 10 to 14 fully expanded yellowish green leaves (Walker and Zareh, 1990); besides, the selected shoots were not pruned. We used the dynamic headspace technique for all volatile collections by enclosing a healthy citrus shoot in a polyethylene terephthalate (PET) bottle $(1.5 \mathrm{~L})$. We cut bottles vertically into halves, and after enclosing the citrus shoot avoiding mechanical damage, we wrapped them with parafilm tape. A purified airstream by activated charcoal (8-20 mesh, Sigma-Aldrich, St. Louis, Missouri, USA) was pumped into the PET bottle at $1000 \mathrm{~mL} \mathrm{~min}^{-1}$ and extracted at $900 \mathrm{~mL} \mathrm{~min}^{-1}$ using a vacuum pump (BOECO, Hamburg, Germany) (Ceballos and Rioja, 2019). The volatiles were trapped into glass columns (13 cm $\times 5 \mathrm{~mm}$ internal diameter) filled with $100 \mathrm{mg}$ Porapak Q (80-100 mesh, Waters Associates, Milford, Massachusetts, USA) tightly inserted at the bottom of each bottle. Before its use, Porapak Q traps were cleaned applying $1 \mathrm{~mL}$ diethyl ether and then conditioned at $220^{\circ} \mathrm{C}$ in an oven under a constant stream of nitrogen. We eluted volatiles passing $1 \mathrm{~mL}$ re-distilled hexane through Porapak columns (Chromatographic grade, Optima Scientific, Green Bay, Wisconsin, USA). We carried out all collections for $24 \mathrm{~h}$ in January 2020, summer season, using an empty bottle under the same conditions and sampling time as control. 


\section{Chemical analysis of BVOCs}

One microliter of the eluted samples was injected in the gas chromatographer coupled to a mass spectrometer (GCMSQP2010 Plus; Shimadzu, Tokyo, Japan). The GC was equipped with an RTx5 capillary column (Crossbond, 5\% diphenyl/95\% dimethyl polysiloxane, $30 \mathrm{~m}, 0.25 \mathrm{~mm}$ internal diameter, $0.25 \mu \mathrm{m}$ film thickness; Restek Corporation, Bellefonte, Pennsylvania, USA). Oven temperature was configured to start at $40{ }^{\circ} \mathrm{C}$ and be held for $1 \mathrm{~min}$ and then be increased to $280^{\circ} \mathrm{C}$ at a rate of $5{ }^{\circ} \mathrm{C} \mathrm{min}^{-1}$. The injection mode was split-less, and helium was used as carrier gas with a constant flow rate of $1.0 \mathrm{~mL} \mathrm{~min}^{-1}$. Acquisition was performed in the mass range from 50 to $500 \mathrm{~m} / \mathrm{z}$, and the ionization was achieved with an electron impact at $70 \mathrm{eV}$ with an ion source at $230^{\circ} \mathrm{C}$.

Volatiles were identified by comparing their retention times and mass spectrums with those in the NIST database v2.0 (National Institute of Standards and Technology, Gaithersburg, Maryland, USA). Chromatographic peaks in the control empty bottle were considered as an artifact of the technique, yet we did not consider peaks presence in the citrus samples. We analyzed compounds that matched at least 70\% of similarity with the NIST database (Müller et al., 2013).

\section{Behavioral responses to citrus plant volatiles}

Olfactory responses of adult females of A. flocossus toward citrus odors were tested in two-choice bioassays using a glass Y-tube as a behavioral arena as described by Li et al. (2014), with slight modifications. We used a Y-tube with an arm length of $15 \mathrm{~cm}$ ( $2.5 \mathrm{~cm}$ internal diameter) designating each arm as one arena zone. Thus, while the Y-tube base was allocated as the decision zone, the opposite arms served as stimulus, and control zones. We loaded $50 \mu \mathrm{L}$ volatiles extracts onto a paper strip $(7 \mathrm{~cm} \times 5 \mathrm{~mm}$, Whatman $\mathrm{nr} 1$ filter paper) and placed it into a glass tube $(10 \mathrm{~cm}$ high and $2.5 \mathrm{~cm}$ outer diameter) connected to each opposite arm of the olfactometer. A charcoal filtered air stream was pulled from the base of the Y-tube at $400 \mathrm{~mL} \mathrm{~min}^{-1}$ by a vacuum pump (BOECO). A group of 30 gravid females of A. floccosus were released at the decision zone, and after $10 \mathrm{~min}$ the number of insects on each zone was recorded. Each group was considered as a replicate and was tested once using a different and clean olfactometer. Each Y-tube was washed with neutral soap and water, rinsed with $90 \%$ alcohol and oven dried. The olfactometer was placed on a black surface, being rotated horizontally in an angle of $90^{\circ}$ after each test. The bioassays were carried out between 10:00 and 15:00 h, at $25 \pm 2^{\circ} \mathrm{C}$ and $65 \pm 5 \% \mathrm{RH}$.

\section{Statistical analysis}

We compared the abundance of each identified compound in the citrus species using the ANOVA procedure, under a completely randomized design, followed by the Tukey's test $(\mathrm{p}<0.05)$. Prior to the procedure, area percentages, representing the abundance, were transformed using arcsine (area) function. We analyzed the number of A. flocossus females counted in the stimulus, control, and decision zones by the two-sided permutation t-test (5000 reallocations), and for the two-choice behavioral test we computed the unstandardized size effect and its bootstrap $95 \%$ confidence interval with 5000 re-samples using the dabest package in R (Ernst, 2004; Ho et al., 2019).

\section{RESULTS AND DISCUSSION}

\section{BVOCs emitted by citrus shoots}

To our knowledge, there was no information about the volatile profile of tangelo shoots; in this study, we registered citronellol and cis-p-mentha-2,8-dien-1-ol just in this species. These compounds have been identified in essential oil of roots and aerial parts of Elionurus hensii K. Schum. (Poaceae) (Yang et al., 2013), and leaves oil of Cymbopogon densiflorus Stapf (Poaceae) (Chisowa, 1997). Other compounds from tangelo volatile profile were shared with other citrus species studied as $\beta$-phellandrene with an abundance of $17.01 \%$, nonanal $(17.87 \%)$, caryophyllene (16.01\%), decanal (15.11\%), D-limonene $(5.57 \%)$ and $\beta$-ocimene $(3.12 \%)$.

Our results indicate that citrus shoots emit mainly monoterpenes such as sabinene, $\beta$-phellandrene, D-limonene, sesquiterpenes as caryophyllene and $\alpha$-farnesene, and aldehydes as nonanal and decanal. Octanal, D-limonene and decanal were detected in all citrus volatile profiles (Table 1). D-Limonene was significantly more abundant in C. xaurantiifolia $(\mathrm{F}=118.15, \mathrm{p}=0.0001)$ followed by mandarin $(11.53 \%)$ and tangelo (5.57\%). Killiny and Jones (2017), in experiments using solid phase micro-extraction (SPME) technique, found a high abundance of limonene $(11.39 \%$ ) in young leaves of $C . \times$ sinensis. Likewise, limonene has been described as a significant compound in volatiles profile of $C$. $\times$ sinensis, C. xlimon, C. xparadisi, C. unshiu, C. grandis, C. reticulata, and C. xaurantium (Asai et al., 2016; Petretto et al., 2016; Patt et al., 2018). Hijaz et al. (2016), using grounded fine powder of 'Mexican lime' (C. xaurantiifolia) leaves 
Table 1. Chemical composition of volatile organic compounds emitted by lime Citrus xaurantiifolia, mandarin C. reticulata and tangelo $C$. reticulata $\times C$. xparadisi in semi-field conditions.

\begin{tabular}{lccc}
\hline & \multicolumn{3}{c}{ Relative abundance (\%) } \\
\cline { 2 - 4 } Compounds & C. $\times$ aurantiifolia & C.reticulata & C.reticulata $\times$ C. $\times$ paradisi \\
\hline Sabinene & - & $12.36 \pm 4.33^{*}$ & - \\
$\beta$-Phellandrene & - & - & $17.01 \pm 2.65$ \\
Octanal & $2.82 \pm 0.63 \mathrm{a}$ & $3.40 \pm 0.83 \mathrm{a}$ & $2.73 \pm 0.56 \mathrm{a}$ \\
2-Ethyl-1-hexanol & $13.96 \pm 3.32 \mathrm{a}$ & - & $4.87 \pm 1.79 \mathrm{~b}$ \\
D-Limonene & $32.44 \pm 2.65 \mathrm{a}$ & $11.53 \pm 3.11 \mathrm{~b}$ & $5.57 \pm 0.87 \mathrm{c}$ \\
$\beta$-Ocimene & $1.90 \pm 0.24 \mathrm{~b}$ & - & $3.12 \pm 0.84 \mathrm{a}$ \\
3,7-Dimethyldecane & $5.87 \pm 1.01 \mathrm{a}$ & - & $6.50 \pm 1.93 \mathrm{a}$ \\
Citronellol & - & - & $2.47 \pm 1.02$ \\
Nonanal & $16.08 \pm 1.45 \mathrm{~b}$ & $28.06 \pm 2.46 \mathrm{a}$ & $17.87 \pm 3.64 \mathrm{~b}$ \\
3-Ethyl-benzandehyde & $4.20 \pm 0.79$ & - & - \\
cis- -Mentha-2,8-dien-1-ol & - & - & $8.89 \pm 1.13$ \\
Decanal & $12.25 \pm 2.19 \mathrm{a}$ & $11.92 \pm 4.42 \mathrm{a}$ & $15.11 \pm 2.03 \mathrm{a}$ \\
Citral & $2.40 \pm 0.28$ & - & - \\
Caryophyllene & - & $22.97 \pm 4.31 \mathrm{a}$ & $16.01 \pm 4.17 \mathrm{a}$ \\
$\alpha$-Farnese & - & $4.95 \pm 0.96$ & - \\
$\beta$-Bisabolene & $7.78 \pm 2.02$ & - & - \\
\hline
\end{tabular}

*Mean abundance $(\mathrm{n}=3) \pm$ standard deviation. Means sharing a letter, for each compound between species, do not differ significantly according to Tukey's test $(\mathrm{P}<0.05)$.

-: Compound not detected.

extracted with liquid nitrogen, found $10.8 \%$ of D-limonene. The volatile profile of $C$. reticulata was characterized by sabinene, D-limonene, nonanal, decanal, caryophyllene and less abundant compounds as octanal and $\alpha$-farnesene. The fruit's peel chemical composition of this species has exhibited a high abundance of limonene (78.02\%) and the presence of $\gamma$-terpinene (15.04\%) (Petretto et al., 2016).

\section{Behavioral response of $A$. floccosus to citrus BVOCs}

Aleurothrixus floccosus females were significantly attracted to volatile extracts from all studied citruses. In the olfactometric bioassay, lime odors elicit the strongest attraction, with $80 \%$ of the individuals choosing this odor source, while $66 \%$ choose mandarin and 63\% tangelo (Figures 1A, 1B, 1C). Togni et al. (2010) in a four-arm olfactometer, found that the silverleaf whitefly B. tabaci remained longer in tomato 'Duradoro' odor. Likewise, the greenhouse whitefly $T$. vaporariorum showed preference to odors of 'Red beauty $F_{1}$ ' tomato plants (Matu et al., 2021).

Lime volatiles attract $13.5 \%$ and $17.1 \%$ more A.foccosus females when compared to mandarin and tangelo respectively (Figures 2A, 2B); whereas A. floccosus did not show differences when they faced to mandarin and tangelo volatiles simultaneously (Figure 2C). The semiochemistry of A. floccosus is unknown in the literature. However, other whiteflies such as $T$. vaporariorum and $B$. tabaci have been extensively studied. Trialeurodes vaporarorium showed preference for flowering odors of basil (Ocimum basilicum) and Mexican marigold (Tagetes minuta), companion plants of tomato (Matu et al., 2021). On the other hand, Sadeh et al. (2017) found that B. tabaci biotypes B and Q were attracted to mature potted plants of rosemary (Rosmarinus officinalis L.) var. '2' unlike to var. '11', which were placed in lemon verbena (Lippia citrodora) fields, confirming that whiteflies can discriminate between compound blends of different ecotypes or genotypes. Islam et al. (2017) detected that tomato plants 'Gan Liang Mao Fen 802 F1' treated with high N levels changes the quantity and quality of BVOCs, which increased the attraction of $B$. tabaci compared to those treated with normal $\mathrm{N}$ levels. Sadeh et al. (2017) when confronted B. tabaci to a range of concentrations of $\beta$-caryophyllene and limonene, found that the insect was attracted to moderate concentrations in contrast to lowest or highest ones, which were indifferent or repellent. Nevertheless, Shi et al. (2016) in a two-choice bioassay with $B$. tabaci observed repellency to $\delta$-limonene whereas Chen et al. (2017) revealed that B. tabaci $\mathrm{Q}$ was attracted to phenols and 2-ethyl-1-hexanol. Sadeh et al. (2017) using a T-shaped glass olfactometer, found that $B$. tabaci was attracted to $0.004-0.025 \mathrm{ppm}$ of $\beta$-caryophyllene. In our study, we detected caryophyllene at moderate abundances in mandarin and tangelo shoots. Hence, studies of potential key compounds at different concentrations from blends of BVOCs emitted by citrus plants are required. 
Figure 1. Number of Aleurothrixus floccosus females attracted to biogenic volatile organic compounds released by A) lime Citrus xaurantiifolia, B) mandarin C. reticulata and C) tangelo $C$. reticulata $\times C$. $\times$ paradisi in the olfactometric bioassay.
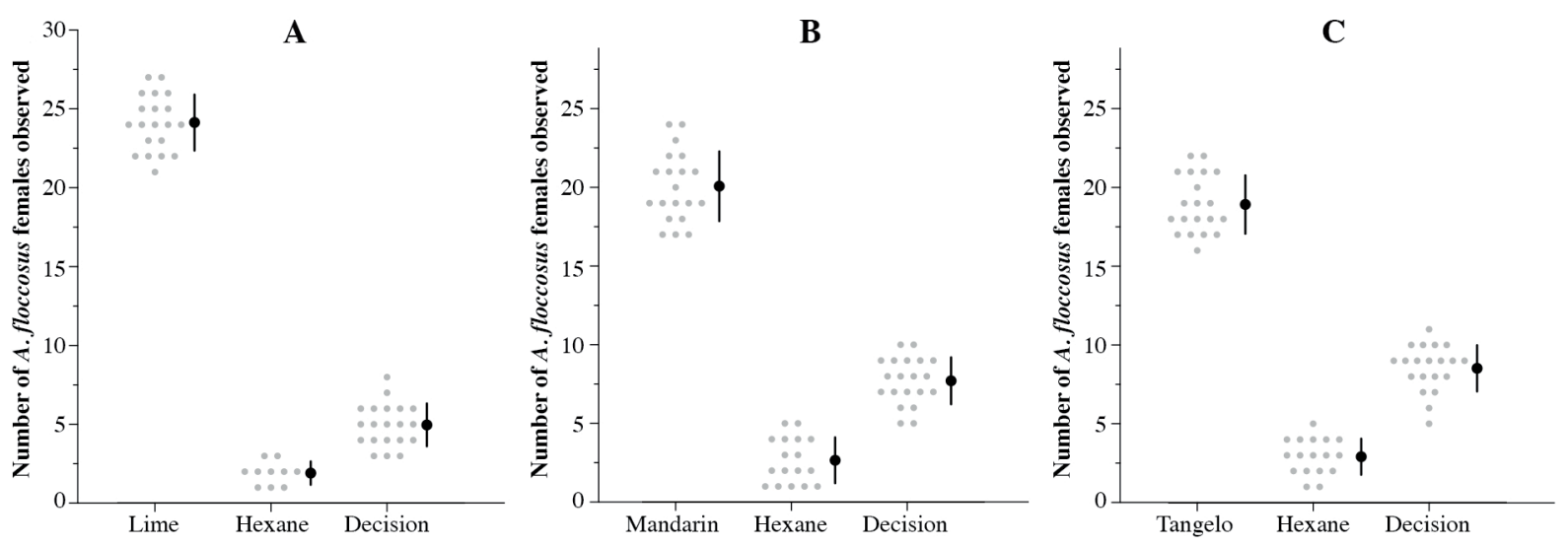

Grey dots represent the number of $A$. floccosus females in each replicate by olfactometer zone. Black dot and vertical solid line represent the estimated mean number of A. floccosus females and its corresponding confidence interval at $95 \%$.

Figure 2. Gardner-Altman estimation plot for number of Aleurothrixus floccosus females in a two-choice test attracted to biogenic volatile organic compounds released by lime Citrus xaurantiifolia vs. mandarin $C$. reticulata (A); lime $C$. xaurantiifolia vs. tangelo $C$. reticulata $\times$ C. $\times$ paradisi $(\mathrm{B})$ and mandarin $C$. reticulata vs. tangelo C. reticulata $\times$ C. $\times$ paradisi $(\mathrm{C})$.
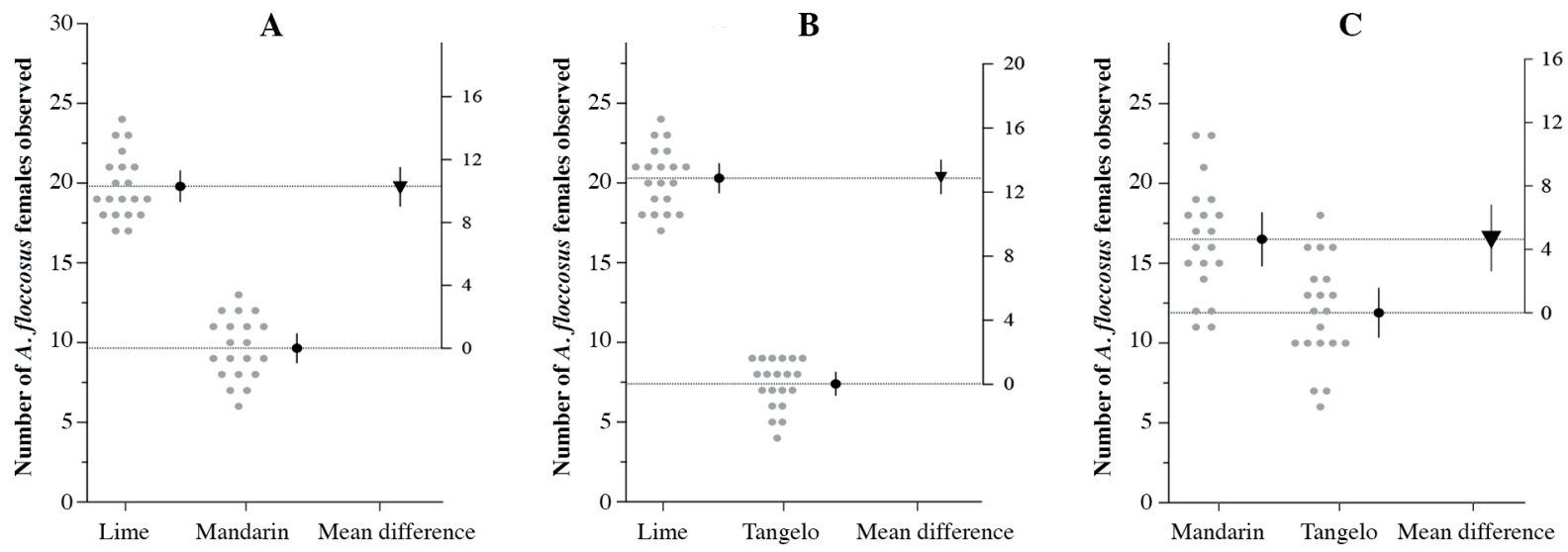

Grey dots represent the number of A. floccosus females in each replicate by olfactometer zone. Black dot and vertical solid line represent the estimated mean number of $A$. floccosus females and its corresponding confidence interval at $95 \%$. The mean difference is plotted on a floating axis on the right as a triangle; the $95 \%$ confidence interval is indicated by the ends of the vertical error bar.

\section{CONCLUSIONS}

Volatile profiles of lime 'Limón de Pica', mandarin 'Oronules', and tangelo 'Minneola' showed significant differences. However, D-limonene and the aldehydes octanal, nonanal and decanal were detected in all citrus species. Our finding revealed that volatiles profiles of citrus species elicit attraction of woolly whitefly (Aleurothrixus floccosus) females, and the potency of the attraction depends on the citrus species. Biogenic volatile organic compounds released by lime 'Limón de Pica' were more attractant than mandarin and tangelo, showing that the citrus woolly whitefly uses chemical information from the host to discriminate between citrus species. Thus, seemingly the lime plants would be more susceptible to infestations of A.floccosus, being necessary studies at physiological and molecular levels. Furthermore, some detected compounds as D-limonene, caryophyllene, 2-ethyl-1-hexanol and aldehydes could be catalogued as key compounds for the attraction of A. floccosus, for which further research are required. Therefore, the present investigation is the first step to obtain crucial information to control and manipulate sustainably the A. floccosus populations across development of sticky baits and slow-release dispensers in citrus orchards, within the context of a clean agriculture and circular economy. 


\section{ACKNOWLEDGEMENTS}

Financial support was supplied by ANID, CONICYT + PAI/Concurso Nacional Inserción en la Academia, Convocatoria 2017 + Folio PAI79170137.

\section{REFERENCES}

Asai, T., Matsukawa, T., and Kajiyama, S. 2016. Metabolic changes in Citrus leaf volatiles in response to environmental stress. Journal of Bioscience and Bioengineering 121:235-241. doi:10.1016/j.jbiosc.2015.06.004.

Belay, D.K., Zewdu, A., and Foster, J.E. 2011. Ecology of the management of the woolly whitefly (Hemiptera: Aleyrodidae), a new invasive citrus pest in Ethiopia. Journal of Economic Entomology 104:1329-1338. doi:10.1603/EC11017.

Bouwmeester, H., Schuurink, R.C., Bleeker, P.M., and Schiesti, F. 2019. The role of volatiles in plant communication. The Plant Journal 100:892-907. doi:10.1111/tpj.14496.

Ceballos, R., and Rioja, T. 2019. Rootstock affects the blend of biogenic volatile organic compounds emitted by 'Hass' avocado. Chilean Journal of Agricultural Research 79:330-334. doi:10.4067/S0718-58392019000200330.

Chen, G., Su, Q., Shi, X., Liu, X., Peng, Z., Zheng, H., et al. 2017. Odor, not performance, dictates Bemisia tabaci's selection between healthy and virus infected plants. Frontiers in Physiology 8:146. doi:10.3389/fphys.2017.00146.

Chisowa, E.H. 1997. Chemical composition of flower and leaf oils of Cymbopogon densiflorus Stapf from Zambia. Journal of Essential Oil Research 9:469-470. doi:10.1080/10412905.1997.9700752.

Darshanee, H.L.C., Ren, H., Ahmed, N., Zhang, Z-F., Liu, Y-H., and Liu, T-X. 2017. Volatile-mediated attraction of greenhouse whitefly Trialeurodes vaporariorum to tomato and eggplant. Frontiers in Plant Science 8:1285. doi:10.3389/fpls.2017.01285.

Ernst, M.D. 2004. Permutation methods: A basis for exact inference. Statistical Science 19:676-685. https://doi.org/10.1214/088342304000000396.

Giliomee, J.H., and Millar, I.M. 2009. The woolly whitefly, Aleurothrixus floccosus (Maskell) (Hemiptera: Aleyrodidae), a potentially serious citrus pest, recorded from South Africa. African Entomology 17:232-233. doi:10.4001/003.017.0216.

Hijaz, F., Nehela, Y., and Killiny, N. 2016. Possible role of plan volatiles in tolerance against huanglongbing in citrus. Plant Signaling \& Behavior 11:e1138193. doi:10.1080/15592324.2016.1138193.

Ho, J., Tumkaya, T., Aryal, S., Choi, H., and Claridge-Chang, A. 2019. Moving beyond P values: data analysis with estimation graphics. Nature Methods 16:565-566. https://doi.org/10.1038/s41592-019-0470-3.

Islam, M.N., Hasanuzzaman, A.T.M., Zang, Z-F., Zang, Y., and Liu, T-X. 2017. High level of nitrogen makes tomato plants releasing less volatiles and attracting more Bemisia tabaci (Hemiptera: Aleyrodidae). Frontiers in Plants Science 8:466. doi:10.3389/fpls.2017.00466.

Johnston, N., and Martini, X. 2020. The influence of visual and olfactory cues in host selection for Bemisia tabaci Biotype B in the presence or absence of Tomato yellow leaf curl virus. Insects 11:115. doi:10.3390/insects11020115.

Kigathi, R.N., Weisser, W.W., Reichelt, M., Gershenzon, J., and Unsicker, S. 2019. Plant volatile emission depends on the species composition of the neighboring. BMC Plant Biology 19:58. doi:10.1186/s12870-018-1541-9.

Killiny, N., and Jones, S.E. 2017. Profiling of volatile organic compounds released from individual intact juvenile and mature citrus leaves. Journal of Plant Physiology 208:47-51. doi:10.1016/j.jplph.2016.11.001.

Klein Koch, C., and Waterhouse, D.F. 2000. The distribution and importance of arthropods associated with agriculture and forestry in Chile. ACIAR Monograph $\mathrm{N}^{\circ} 68$. Australian Centre for International Agricultural Research (ACIAR), Canberra, Australia.

Li, Y., Zhong, S., Qin, Y., Zhang, S., Gao, Z., Dang, Z., et al. 2014. Identification of plant chemicals attracting and repelling whiteflies. Arthropod-Plant Interactions 8:183-190. doi:10.1007/s11829-014-9302-7.

Markheiser, A., Rid, M., Biancu, S., Gross, J., and Hoffmann, C. 2020. Tracking short-range attraction and oviposition of European grapevine moths affected by volatile organic compounds in a four-chamber olfactometer. Insects 11:45. doi:10.3390/insects11010045.

Matu, F.K., Murungi, L.K., Mohamed, S., and Deletre, E. 2021. Behavioral response of the greenhouse whitefly (Trialeurodes vaporariorum) to plant volatiles of Ocimum basilicum and Tagetes minuta. Chemoecology 31:1-16. doi:10.1007/s00049-020-00327-z.

Müller, A., Faubert, P., Hagen, M., Zu Castell, W., Polle, A., Schnitzler, J.-P., et al. 2013. Volatile profiles of fungi - Chemotyping of species and ecological functions. Fungal Genetics and Biology 54:25-33. doi:10.1016/j.fgb.2013.02.005.

ODEPA-CIREN. 2019. Catastro frutícola Región de Tarapacá, principales resultados. Oficina de Estudios y Políticas Agrarias (ODEPA), y Centro de Información de Recursos Naturales (CIREN), Santiago, Chile. Available at https://www.odepa.gob. cl/wp-content/uploads/2019/08/catastroTarapaca2019.pdf (Accessed January 2021).

Patt, J.M., Robbins, P.S., Niedz, R., McCollum, G., and Alessandro, S. 2018. Exogenous application of the plant signalers methyl jasmonate and salicylic acid induces changes in volatile emissions from citrus foliage and influences the aggregation behavior of Asian citrus psyllid (Diaphorina citri), vector of Huanglongbing. PLOS ONE 13:e0193724. doi:10.1371/journal.pone.0193724. 
Petretto, G.L., Sarais, G., Maldini, M.T., Foddai, M., Tirillini, B., Rourke, J.P., et al. 2016. Citrus monstruosa discrimination among several Citrus species by multivariate analysis of volatiles: a metabolomics approach. Journal of Food Processing and Preservation 40:950-957. doi:10.1111/jfpp.12674.

Rioja, T., Ceballos, R., Fernandez, N., and Curkovic, T. 2021. Autumnal recruitment of mite's predators by herbivore-induced plant volatiles in avocado (Persea americana Mill. cv. Hass) infested with Oligonychus yothersi (Acari: Tetranychidae). International Journal of Acarology 47(4):352-360. doi:10.1080/01647954.2021.1913220.

Saad, K.A., Roff, M.N., Shukri, M.M.A., Mirad, R., Mansour, S.A.A., Abuzid, I., et al. 2013. Behavioral responses of whitefly Bemisia tabaci (Hemiptera: Aleyrodidae) in relation to sex and infestation status of their host plants. Academic Journal of Entomology 6(3):93-99. doi:10.5829/idosi.aje.2013.6.3.7644.

Sadeh, D., Nitzan, N., Shachter, A., Chaimovitsh, D., Dubai, N., and Ghanim, M. 2017. Whitefly attraction to rosemary (Rosmarinus officinialis L.) is associated with volatile composition and quantity. PLOS ONE 12:e0177483. doi:10.1371/journal.pone.0177483.

Shi, X., Chen, G., Tian, L., Peng, Z., Xie, W., Wu, Q., et al. 2016. The salicylic acid-mediated release of plant volatiles affects the host choice of Bemisia tabaci. International Journal of Molecular Sciences 17:1048. doi:10.3390/ijms 17071048

Sundararaj, R., Selvaraj, K., Swamy, C.M., Ranjith, M., and Sumalatha, B.V. 2020. First record of the invasive woolly whitefly Aleurothrixus floccosus (Maskell) from India.Indian Journal of Entomology 82:88-91 .doi:10.5958/0974-8172.2020.00022.X

Tello, V., Peralta, O., and Rioja, T. 2019. Voltinism of Aleurothrixus floccosus Maskel (Hemiptera: Aleyrodidae) in an oasis agroecosystem in the Atacama Desert, Tarapacá Region, Chile. IDESIA 37:5-7. doi:10.4067/S0718-34292018005002303.

Tello, V., Solimano, E., and Giliomee, J.H. 2014. Life table parameters of the woolly whitefly Aleurothrixus floccosus (Hemiptera: Aleyrodidae) and its parasitoid Cales noacki (Hymenoptera: Aphelinidae). European Journal of Entomology 111:251-256. doi:10.14411/eje.2014.020.

Togni, P.H.B., Laumann, R.A., Medeiros, M.A., and Sujii, E.R. 2010. Odour masking of tomato volatiles by coriander volatiles in host plant selection of Bemisia tabaci biotype B. Entomologia Experimentalis et Applicata 136:164-173. doi:10.1111/j.1570-7458.2010.01010.x.

Walker, G.P., and Zareh, N. 1990. Leaf age preference for oviposition by three species of whitefly on lemon. Entomologia Experimentalis et Applicata 56:31-45. doi:10.1111/j.1570-7458.1990.tb01379.x.

Yang, Y., De Cian, M.C., Nsikabaka, S., Tomi, P., Silou, T., Costa, J., et al. 2013. Volatile fraction composition and total phenolic and flavonoid contents of Elionurus hensii-antioxidant activities of essential oils and solvent extracts. Natural Product Communications 8:655-661. doi:10.1177/1934578X1300800528. 